\title{
Gendered role communication in marketing blue-collar occupational gear and clothing in the United States
}

\author{
Seoha Min ${ }^{*}$
}

*Correspondence:

s_min@uncg.edu

The Department

of Consumer, Apparel,

and Retail Studies, The

University of North Carolina

at Greensboro, 355 Stone

building, Greensboro, NC

27402, USA

\begin{abstract}
Considering the need for gender equity in the workforce, this research explores social construction of gender; how that construction relates to work; and, subsequently, how gender construction influences the design and marketing of work clothing and personal protective equipment (PPE) for women working in blue-collar occupations. To explore the phenomenon, a content analysis of products and advertising images in seven websites selling blue-collar work clothes and PPE was used. Collected data suggests work clothing and PPE designed for women is limited in terms of size, design, and number of products available. It was also found that there exists a cultural discomfort with portraying women as competent blue-collar professionals in the advertisement of work clothing. The research provides a discussion of guiding ideas for improvement in the design and marketing of products for women workers in blue-collar occupations. Findings suggest design and marketing images could be improved to better reflect and appeal to women purchasing and using these products.
\end{abstract}

Keywords: Work clothing, Personal protective equipment (PPE), Blue-collar occupation, Women

\section{Introduction}

Despite the job market getting competitive, companies are starting to report lack of skilled workers, especially in blue-collar occupations (Hartman 2015). Postlethwaite (2014) wrote in the Welding Journal that there will be a shortage of 290,000 skilled welders in the United States by 2020. In this regard, companies and government policymakers have tried to educate and recruit women as a potential solution of the coming blue-collar labor shortage (Hartman 2015). However, despite these attempts by the companies and the government, blue-collar occupations remain a sector of the workforce where women find it hard to work due to various hostile obstacles. In order to attract more women to blue-collar occupations, obstacles that female workers in blue-collar occupations face need to be addressed and discussed.

Female workers often encounter various obstacles, such as hostile working environments, including unpleasant behavior by male colleagues, public questioning of a woman's competence, and resentment that female workers are taking men's jobs (Ferguson and Sharples 1994). Among the various obstacles that female workers face in the

(C) 2015 Min. This article is distributed under the terms of the Creative Commons Attribution 4.0 International License (http:// creativecommons.org/licenses/by/4.0/), which permits unrestricted use, distribution, and reproduction in any medium, provided you give appropriate credit to the original author(s) and the source, provide a link to the Creative Commons license, and indicate if changes were made. 
blue-collar occupations, how female workers in blue-collar occupations have been portrayed in the media is of grievous concern. Kleiman (1988) indicated that female workers in blue-collar occupations are often portrayed as "helpless victims" and "unable to act in their own interests". Female workers in blue-collar occupations are still depicted negatively in the media (Jhally and Alper 2005). The negative stereotype of female workers in blue-collar occupations has hindered their entrance to the occupations, however, only few studies have investigated this issue. In this regard, exploration of how female workers in blue-collar occupations are communicated in the media is highly needed as an initial step of resolving the issue.

The research explored how female workers in blue-collar occupations have been portrayed in the design and marketing of clothing and personal protective equipment (PPE) based on a symbolic interactionism framework. Symbolic interaction involves representing and communicating roles to others (Charon 1992). Considering the fact that people tend to wear clothing according to society's norms or expectations for the particular role (Kaiser 1985), exploration of the design and marketing of clothing and PPE for the female workers will provide an insight of how the roles of the female workers are understood and communicated. To achieve the research purpose, researcher executed a content analysis of product and advertisement images from seven company websites selling blue-collar work clothing and PPE. By executing content analysis, the researcher provides empirical data about work clothing design, marketing, and availability. Going beyond a count of clothing and examination of advertising images presented on company websites, this article also provides a discussion of guiding ideas for improvement in the design and marketing of products for women workers in blue-collar occupations.

\section{Literature review}

\section{Symbolic interactionism}

A symbolic interactionism framework was applied to understand companies' product offerings for female workers in blue-collar occupations and how those products are marketed. Simply stated, symbolic interactionism is a conceptual framework that proposes that individual behavior is mainly a result of social interaction (Blumer 1969). Blumer (1969) stated that "to identify and understand the life of a group it is necessary to identify its world of objects; this identification should be in terms of the meanings objects have for the members of the group (p. 69)." That is why objects are central to the symbolic interactionism perspective, because they constitute the world surrounding a human being and a human group (Blumer and Morrione 2004, p. 95). In this regard, the researcher in this study decided to classify the work clothing and personal protective equipment (PPE) in blue-collar occupations as a social object and a symbol that attain meaning through social interaction.

Symbolic interaction involves role taking as well as representing and communicating roles to others (Charon 1992). McCall and Simmons (1978) added that social roles are how the individual likes to think of him- or herself while occupying a position and that this view is usually idealized. Thus, role theory deals with the organization of social behavior on an individual and collective level (Stryker 2001). Roles help the understanding of the relationship among micro and macro levels of society by observing (Stryker 2001) (a) the actions and feelings of an individual that might differ according 
to a situation or position and (b) similar behaviors of different individuals in the same relationship. The interactionist definition of role accepts roles as not fixed or prescribed but as constantly negotiated by individuals (Lynch 2007). That is why symbolic interaction includes role taking, which makes human interaction complex and unpredictable (Charon 1992). Furthermore, these roles are not separated; they are woven together and mutually influence one another (McCall and Simmons 1978).

According to Goffman's (1959) role theory, an actor performs many roles related to pre-established patterns of action that can unfold during the actor's performance. MillerSpillman et al. (2012) further stated that role theory helps us understand how dress is a part of the various roles we occupy in a group or society. Consumers are provided work clothing and PPE that are considered socially appropriate by companies according to society's norm or expectations for the particular role. Through this process, people are encouraged to adopt and develop certain traits that are often referred to as masculine and feminine.

\section{Women in blue-collar occupations}

The US Department of Labor (2012) estimated that the female workers comprised $46.9 \%$ of the overall US workforce in 2012, and a significant portion of these women is pursuing careers in sectors that are traditionally male-dominated such as blue-collar occupations. Blue-collar workers are defined as wage earners in jobs involving manual labor requiring technical and vocational skills (Ferguson and Sharples 1994). Occupations that require physical works, such as carpenters, plumbers, electricians, machinists, and construction workers, are considered as traditional blue-collar occupations (Mansfield et al. 1991). Hartman (2015) indicated that "employer groups, labor unions, women's advocacy groups and government policymakers all see women as part of a potential solution to the coming blue-collar labor shortage." However, he mentioned that progress of recruiting more women to blue-collar occupations has been slow due to several obstacles.

Several scholars have indicated that female workers in male-dominated careers often experience problems of segregation (DeFleur 1985; Hill 1986; Bergmann 2011). Bergmann (2011) indicated that employers often anticipate that hiring female workers "will reduce productivity, and can create crisis situation" (p. 91). Because of their gender, female workers in the workplace experience difficulties such as "sexual harassment and discrimination, including hostility and sabotage, withholding of training opportunities, and supervisory indifference" (Mansfield et al. 1991, p. 66). In addition to these obstacles, according to Goldenhar and Sweeney (1996), tradeswomen reported other important health and safety concerns and are more vulnerable to these concerns compared to their tradesmen counterparts. Walshok (1981) also indicated that female workers in male-dominant careers face many obstacles, including lack of acceptance by male coworkers, lack of support from family and friends, and the necessity of adjusting to the dominant "male culture."

The low representation of female workers in most blue-collar occupations is also one of challenges that female workers have experienced (Browne 2002). Browne (2002) explained that gender differences that appear to influence on "the representation of women in blue-collar jobs include differences in occupational interests, ability, and in job attribute preferences, such as a disinclination among women toward physically 
strenuous, dirty, and dangerous occupations and a preference for flexible hours (p. 63)". Due to the low representation of the female workers in blue-collar occupations, often times, they are depicted negatively in the media (Jhally and Alper 2005). Since the number of women in such careers has increased (National Association of Women in Construction, 2013) and will likely continue to increase, it is of great importance to identify how female workers have been depicted in the media and to explore creative solutions to communicate their images for positive integration in the workplace.

\section{Blue-collar work clothing and gender}

Clothing serves various communicative functions. Especially, one's identity is often communicated through clothing (Kaiser 1985). In addition to communicating self, clothing has a significant impact on the enhancement of self. When used positively, clothing contributes to feelings of self-acceptance (Gibbins 1969). In addition, Kwon (1994) found that positive feelings toward one's clothing were positively related to self-perceived emotion, sociability, and work competency. Wagner, Kim, and Gordon (2013) also explored significant connections between satisfaction with work clothing and PPE, self-efficacy, and overall satisfaction of trade work. Therefore, it would be significant to promote one's perceptions about work clothing to improve one's overall satisfaction in the workplace.

Women who work in blue-collar occupations, however, often experience difficulties with their work clothing. Goldenhar and Sweeney (1996) found that there was a lack of clothing and equipment specifically designed for women in construction. As a consequence, female workers often have no choice but to wear protective clothing and equipment that are designed for males. Improperly fitting gloves, boots, hard hats, overalls, and hand tools increase the likelihood of exposure to occupational hazards. Wagner et al. (2013) explored the need for properly designed work clothing and PPE for tradeswomen. In addition, Goldenhar and Sweeney (1996) indicated that fitting in with the male crew was a challenge to all the tradeswomen who participated in the research. Female workers in blue-collar occupations were not allowed to behave as female construction workers nor to fully concentrate on their work (Tork 2008). They had to act like men or constantly worry about impressing their male co-workers. Tork (2008) analyzed data from an interview with one female laborer.

[She has to be] a part of the masculine culture. She stated that her male co-workers treat her "just like one of the guys." She did not mention being uncomfortable with her relationships with male co-workers but this could be because she has internalized some kind of male character as another way to cope with the gendered stress

(Tork, 2008, p. 29).

This shows that women in blue-collar occupations struggle not only with finding work clothing that fits but also with being able to identify and be identified as "female" in their work clothing. Levy stated that "all commercial objects have a symbolic character, and making a purchase involves an assessment-implicit or explicit-of this symbolism, to decide whether or not it fits" (Levy 1959, p. 117). Taking into account these issues, it is worthwhile to explore what kinds of clothing and PPE are available for women bluecollar workers and the ways that marketing images of women in these clothes and PPE are constructed as advertising images that can influence an individual's self-image. 


\section{Research questions}

The purpose of the research is to understand how female workers in blue-collar occupations have been portrayed in the design and marketing of clothing and PPE. Three research questions were generated to achieve the research purpose. First, how many work clothes and gear are presented for male and female workers in blue-collar clothing company websites? Second, how are products meant for men differentiated from products meant for women? Third, what is communicated in the advertisements, i.e., what images and messages are sent in attempting to sell and make these clothes appealing to the consumer? The available products for the female workers as well as how they were pictured in advertisements are a result of social interaction.

\section{Method}

Bell (2001) stated that "visual content analysis is a systemic, observational method used for testing hypothesis about the ways in which the media represent people, events, situations, and so on" (p. 14). Content analysis is often associated with investigations of the way social issues are represented in the mass media (Van Leeuwen and Jewitt 2001). Therefore, a visual content analysis of images of products and advertisements in websites dealing with blue-collar work clothing was implemented for this study. To conduct the visual content analysis, product images were examined to assess what kind and how many products are available as the first step. Second, types of products and messages in advertisements were content analyzed to explore links between gender and images communicated in the advertisements.

\section{Scope}

Websites were located through a Google search with the keywords "work clothing" and "blue-collar work clothing". As a result, 17 websites were extracted from the search. As a preliminary study, product images and advertisements were collected from the websites in November 2013. Through analyzing the collected data, it appeared that 10 websites among 17 do not deal with both work clothing and PPE at the same time. Therefore, the researcher decided to focus on the remaining seven websites as the sample of the study to stay on the research scope.

While those working in and employing people in blue-collar occupations may not buy all or even some of their clothing or PPE from online sources, there are a number of reasons company websites were examined.

- First, and maybe most significantly, the company website is a location where the company itself has full control over the brand image presented.

- Websites of the clothing and product companies also have their products in brick and mortar stores.

- Retail e-commerce revenue from apparel and accessories sales amounted to 38 billion US dollars in 2012 and this number is growing (Statistica 2014).

- Clothing is one of the most common product categories purchased online (Statistica 2014).

- More female consumers are shopping on the internet than male consumers (Girard et al. 2003). 
- Women in blue-collar occupations, without data presented in these pages, know of the lack of size and product availability via personal experience (Wagner et al. 2013).

- Consumers whose needs are dissimilar to the majority are more likely to shop online (Choi and Bell 2011).

\section{Procedure}

Product images and advertisements were collected from the seven websites from February to March 2015 and then analyzed. In terms of product images, the researcher collected images of work clothes and PPE presented in the websites. After the data collection, the product images were analyzed based on the following: (1) What is the count of products available for men vs. women? (2) How are products meant for men differentiated from products meant for women? In terms of advertisement images, the researcher collected images from online advertisements and catalogues where models are wearing the products. The images were categorized and analyzed based on following: (1) Count of images of men vs. images of women; (2) Action (or non) of the person in the image; (3) Description of images of men vs. images of women (background, facial expression, ethnicity, body images, the way they wear clothing...etc.).

Van Leeuwen and Jewitt (2001) indicated questions regarding priority/salience of media may be addressed using content analysis. The following criteria were used to analyze the product images and the advertisements. First, all the products in the websites were considered work clothes in blue-collar occupations. Analysis included both male and female models. Although the size of the advertisements varied significantly, each ad for a product or brand was counted as one regardless of size. The race of models featured in advertisements was categorized as either white or a person of color. Background of the image including weather/sky, location (e.g. on land or on water or in a machine, field or other) was noted. Finally activity of the person or people in the image was analyzed.

\section{Reliability}

The reliability of analysis was determined. Two researchers independently analyzed advertisement images using the coding sheet developed for the study. For the accuracy of coding, the coder analyzed sample issues at least twice. The reliability was calculated by dividing agreements by total items through SPSS version 21 . A reliability of .95 was found, and thus relative reliability was established (Hair et al. 2010).

\section{Results and discussion}

Based on the findings from the data collection, the three research questions were explored. The following is a discussion of the findings with details that support and explain the three research questions.

1. How many work clothes and gear are presented for male and female workers in bluecollar clothing company websites?

A count of 1904 product images was collected from the seven websites. Among them, only 557 (22.63\%) work clothing and PPE were listed for women specifically (see Table 1). The products were categorized by 10 different types of work clothes and 
Table 1 The number of products available for male and female workers

\begin{tabular}{|c|c|c|c|c|}
\hline \multirow[t]{2}{*}{ Company } & \multicolumn{2}{|c|}{ References per gender } & \multicolumn{2}{|c|}{$\%$ of references per gender } \\
\hline & Male & Female & Male (\%) & Female (\%) \\
\hline Company A & 186 & 68 & 73.23 & 26.77 \\
\hline Company B & 292 & 0 & 100.00 & 0.00 \\
\hline Company C & 824 & 194 & 80.94 & 19.06 \\
\hline Company D & 32 & 9 & 78.05 & 21.95 \\
\hline Company E & 75 & 17 & 81.52 & 18.48 \\
\hline Company F & 300 & 251 & 54.45 & 45.55 \\
\hline Company G & 195 & 18 & 91.55 & 8.45 \\
\hline Total & 1904 & 557 & 77.37 & 22.63 \\
\hline
\end{tabular}

protective gear. These product categories were the following: shirt, t-shirt, pants, jacket, coverall, vest, highly visible cloth, headgear, gloves, and shoes. Among the seven companies, Company B did not provide any products for female workers. Company G did offer both work clothing and PPE for male workers, but no working clothing for female workers. The result indicates that female workers in blue-collar occupations have less available options for work clothing and PPE compare to male workers.

\section{How are products meant for men differentiated from products meant for women?}

Based on the collected data, researcher explored how products designed and marketed for male are different from those for female workers. As a result, the research found significant discrepancy in size, fit, and color options available for male and female workers.

First, available sizes and fit options for female workers were relatively limited compared to male sizing options (see Table 2). For example, Company A provided eight sizes for male workers while there were only six available sizes for female workers. In addition, Company $\mathrm{C}$ listed five different fit options of male work clothing-straight fit, relaxed fit, traditional fit, original/dungaree fit, and loose fit. However, the website provided only three different fit options for female workers—slim/modern fit, original fit, and relaxed

Table 2 List of available size options for male and female workers

\begin{tabular}{lll}
\hline Company name & $\begin{array}{l}\text { Available size options } \\
\text { for male worker }\end{array}$ & $\begin{array}{c}\text { Available size options } \\
\text { for female worker }\end{array}$ \\
\hline Company A & $\mathrm{S}-6 \mathrm{XL}$ & $\mathrm{S}-4 \mathrm{XL}$ \\
Company B & $\mathrm{XS}-4 \mathrm{XL}$ & - \\
Company C & $\mathrm{S}-4 \mathrm{XL}$ & $\mathrm{XS}-2 \mathrm{XL}$ \\
Company D & Big/tall options available & $\mathrm{S}-\mathrm{XL}$ \\
Company E & $\mathrm{M}-2 \mathrm{XL}$ & $\mathrm{S}-3 \mathrm{XL}$ \\
Company F & $\mathrm{S}-6 \mathrm{XL}$ & $\mathrm{XSM}-2 \mathrm{XL}$ \\
& $\mathrm{SM}-4 \mathrm{XL}$ & \\
Company G & Tall option available & - \\
\hline
\end{tabular}

Source: based on sampled company websites 
fit. Also, three websites out of seven provided apparel with big/tall options for male workers while none of seven websites provided big/tall options for female workers.

The findings are supported by previous research where women in blue-collar occupations discuss lack of availability of properly fitting work clothing items (Ferguson and Sharples 1994; Goldenhar and Sweeney 1996; Wagner et al. 2013). As a consequence, female blue-collar workers often have no choice but to wear work clothing and PPE designed for male workers. Goldenhar and Sweeney 1996 indicated that improperlyfitting clothing and PPE are significant concerns of women workers in the construction field because they increase the likelihood of experiencing occupational injuries.

Interestingly, Company A and $\mathrm{C}$ offered products with raspberry, pink, rose, and pastel colors only in women's apparel and PPE categories. In an article for Working Mother, "Inside the Lives of Construction Moms" (Bowers 2013), women in the construction field were profiled. The article included a couple lines discussing wearing of the color pink-the women don't wear it at work (Bowers 2013). Even though one woman stated pink was her favorite color, she said she would never don a pink hard hat (Bowers, 2013). While the vast majority of women do not go to work wearing pink or insisting all tools needed at their job be pink, the color pink is common in blue-collar clothes and gear made for women.

Colors of clothing are culturally coded as masculine or feminine. According to Gleeson and Frith (2004), pink apparel is associated with immature feminine identity. Also, Gleeson and Frith (2004) notes pink represents positive, innocent, asexual, and immature femininity. In view of the fact that female workers in blue-collar occupations may not want to communicate the above-mentioned meanings in the work place and this color is not commonly worn by co-workers. Pink work clothing and PPE would seem to not be the desired color choice for these workers.

3. What is communicated in the advertisements i.e., what images and messages are sent in attempting to sell and make these clothes appealing to the consumer?

In terms of analysis of advertisement images, the researcher collected 79 advertisement images from the seven websites. Interestingly, all workers in the advertisement images and the videos appeared to be young or middle-age European-Americans, implying that this demographic is more appropriate for blue-collar occupations than other populations who are older or have other ethnicities. As discussed earlier, there is a shared culture that someone who is not white and male could not be a competent tradesperson (MacLean 2006; Paap 2006), and the notion appears in these images.

Among 79 images, male workers appeared in 34 images (43.03\%) while female workers appeared in 45 images. This difference may seem negligible in term of the number count. However, if one looks at the images where workers are engaged in an activity, there is a profound contrast in how each gender is depicted which is deeply concerning. Women workers in the images are walking (36.36\%), bending over to the ground (13.64 \%), carrying something $(9.09 \%)$, taking a pose for the photograph $(9.09 \%)$, weeding a garden ( $9.09 \%)$, holding an object (4.55\%), rowing peddles (4.55\%), arranging flowers (4.55\%), cutting a rope $(4.54 \%)$, and arranging crops $(4.54 \%)$. On the other hand, male workers in the images are engaged in more professional activities such as fixing machinery (30\%), driving a truck (30\%), hammering/driving a screw (20\%), tightening a rope 
$(10 \%)$, riding a motorbike $(10 \%)$. Note that female workers in 23 images and male workers in 24 images were not engaged in any activity so were not counted in the statistics above. The above results indicate that there is definitely a strong gender bias towards communicating male workers as being more fit for blue-collar occupation than female counterparts in the images.

In addition, male workers in the images were often placed in work environment $(\mathrm{n}=30,88.2 \%)$ that often included heavy machinery and/or grey and stormy skies (see Fig. 1). The images of women were more serene with sunny skies and little machinery present $(n=36,80 \%)$. Men were collaborating with other men in a number of the images, but women were pictured alone. In terms of facial expression, $60.00 \%$ of female workers $(\mathrm{n}=27)$ are smiling while $40.00 \%$ are neutral $(\mathrm{n}=18)$. On the other hand, only $8.82 \%(\mathrm{n}=3)$ of male workers are smiling while $58.82 \%(\mathrm{n}=20)$ are neutral and $32.35 \%(\mathrm{n}=11)$ are clenching their eye brows. The result indicates male workers in the images are paying more attention to the tasks than female workers.

The results show that male workers were shown as more skillful and professional than female workers in the advertising images. The result indicates that the roles given to the female workers are still "female" and "outsider," unlike male blue-collar workers and there exists a cultural discomfort with portraying females as competent blue-collar professionals in the advertisement of work clothing.

\section{Conclusions}

Based on symbolic interactionism, the research explored how female workers in bluecollar occupations have been portrayed in the design and marketing of clothing and PPE. Consumers are provided work clothing and PPE that are considered socially appropriate by companies according to society's norms or expectations for the particular role. Through this process, people are encouraged to adopt and develop certain traits that are

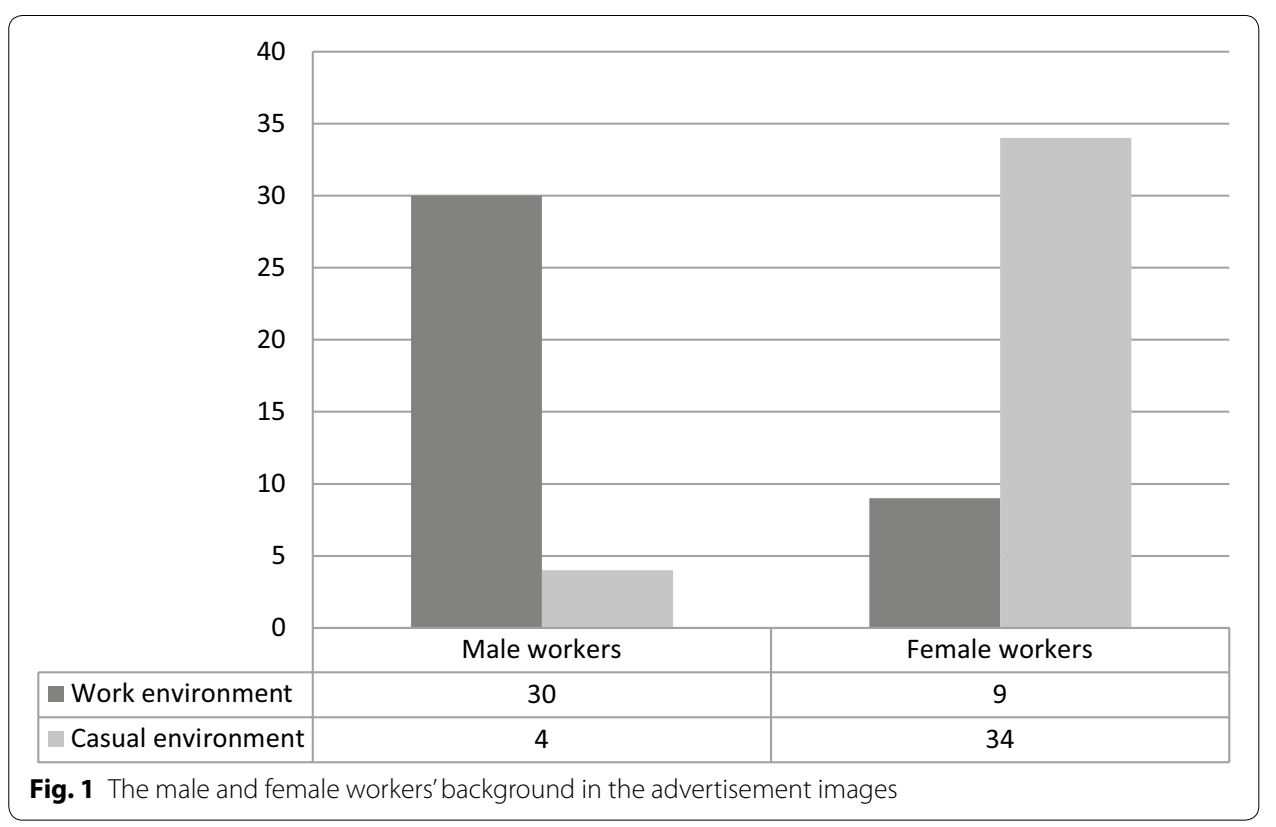


often referred to as masculine or feminine. In this regard, the researcher classified the work clothing and PPE in blue-collar occupations as a social object and a symbol that attains meaning through social interaction. Based on the findings, the researcher drew empirical implications from a theoretical discussion of the findings, as follows.

This research presents empirical data supporting an argument for a new guiding perspective in design and marketing of products intended for women engaged in the traditionally male-dominated fields known as blue-collar occupations. Data present evidence of lack of work clothing and PPE for women. Data suggest that well-designed and constructed female workers' clothing and PPE that helps women workers harmoniously fit in with male co-workers and communicate their female gender would be desirable.

Pettinger (2005) stated that material objects such as retail products are part of the set of gendered social relationships prevalent at a certain context. Within the given context, the remarkably limited number and available sizes of female workers' work clothing and PPE indicate the notion that male workers are better suited for blue-collar occupations. Furthermore, pink products could not only not be the desired color choice for these workers but could also reinforce the perception. Therefore, designers and manufacturers need to pay careful attention when examining size, fit, and distribution of clothing and look beyond the color pink for ways to communicate femininity and/or femaleness (Johnson and Learned 2004).

The results also show that male workers were shown as more skillful and professional than female workers in the advertising images. Since women blue-collar workers face many barriers arising from a culture that often negates or demeans their existence, these workers would likely welcome more diverse designs and innovative and celebratory advertisements. Companies could create more positive images of women doing things other than walking in a meadow and could create more images of women engaging with other women and men in blue-collar occupational tasks. These could be prepared in ways that do not negate masculinity but rather celebrate the fact that women and men can work together well in all occupations.

\section{Limitations and future research}

The study should be viewed as a first step with opportunities for further investigation. The limitations to overcome and suggested future research are described here. First, for this study, samples were restricted to the seven websites aimed at consumers in the United States. Also, in-store items and displays were not included in data collection. This may limit the ability to generalize the findings. Thus, it will be beneficial to collect more extensive data to deepen the understanding of the subject matter. Second, how consumers react to the product and advertisement images was not investigated. For future research, surveys of or interviews with women in these fields about their clothing choices and purchasing behaviors for work-related garments need to be conducted. Also, it will be significant to explore how they have struggled with the limited clothing and PPE options available for them. Third, the factors companies consider when designing and marketing the products were not investigated. For future research, it will be beneficial to conduct in-depth interviews with the companies to explore the phenomenon from the perspective of designers and marketers. 
Received: 3 June 2015 Accepted: 13 November 2015

Published online: 08 December 2015

\section{References}

Bell, P. (2001). Content analysis of visual images. In Van Leeuwen, Jewitt (Ed.), Handbook of visual analysis (pp. 10-34). Thousand Oaks, CA: Sage.

Bergmann, B. R. (2011). Sex segregation in the blue-collar occupations: women's choices or unremedied discrimination? Comment on England. Gender \& Society, 25(1), 88-93. doi:10.1177/0891243210389813.

Blumer, H. (1969). Symbolic interactionism: perspective and method. Englewood Cliffs: Prentice-Hall.

Blumer, H., \& Morrione, T. J. (2004). George Herbert Mead and human conduct. Walnut Creek: AltaMira Press.

Bowers, K. (2013). Inside the lives of construction moms. Working Mother. Retrieved 25 Aug 2015. http://www.workingmother.com/workplace/inside-lives-construction-moms.

Browne, K. (2002). Biology at work: rethinking sexual equality. Piscataway: Rutgers University Press.

Charon, J. M. (1992). Symbolic interactionism: an introduction, an interpretation, an integration. Englewood Cliffs: Prentice-Hall.

Choi, J., \& Bell, D. R. (2011). Preference minorities and the Internet. Journal of Marketing Research, 48(4), 670-682. doi:10.1509/jmkr.48.4.670.

DeFleur, L. (1985). Organizational and ideological barriers to sex integration in military groups. Work and Occupations, 12(2), 206-228. doi:10.1177/0730888485012002005.

Ferguson, T. C., \& Sharples, M. (1994). Blue-collar women: trailblazing women take on men-only jobs. Liberty Corner: New Horizon Press.

Gibbins, K. (1969). Communication aspects of women's clothes and their relation to fashionability. British Journal of Social and Clinical Psychology, 8(4), 301-312.

Girard, T., Korgaonkar, P., \& Silverblatt, R. (2003). Relationship of type of product, shopping orientations, and demographics with preference for shopping on the Internet. Journal of Business and Psychology, 18(1), 101-120. doi:10.102 3/A:1025087021768.

Gleeson, K., \& Frith, H. (2004). Pretty in pink: Young women presenting mature sexual identity. In A. Harris (Ed.), All about the girl: culture, power, and identity (pp. 103-113). New York: Routledge.

Goffman, E. (1959). The presentation of self in everyday life. New York: Doubleday.

Goldenhar, L. M., \& Sweeney, M. H. (1996). Tradeswomen's perspectives on occupational health and safety: a qualitative investigation. American Journal of Industrial Medicine, 29(5), 516-520. doi:10.1002/ (SICI) 1097-0274(199605)29:5<516:AID-AJIM11>3.0.CO;2-3.

Hair, J. F., Black, W. C., Babin, B. J., \& Anderson, R. E. (2010). Multivariate data analysis: a global perspective (8th ed.). Upper Saddle River: Pearson.

Hartman, M. (2015). Women lag in well-paid blue-collar jobs. Marketplace. Retrieved 25 Mar 2015. http://www.marketplace.org/topics/economy/women-lag-well-paid-blue-collar-jobs.

Hill, R. (1986). Dimensions of work. Beverly Hills: Sage.

Jhally, S., \& Alper, L. (2005). Class dismissed: how TV frames the working class [Motion picture]. United States: Media Education Foundation.

Johnson, L., \& Learned, A. (2004). Don't think pink: what really makes women buy - and how to increase your share of this crucial market. New York: AMACOM.

Kaiser, S. B. (1985). Social psychology of clothing and personal adornment. Upper Saddle River: Prentice Hall.

Kleiman, C. (1988, February 29). Stereotypes plaguing blue-collar women, too. Chicago Tribute. Retrieved 25 Mar 2015. http://articles.chicagotribune.com/1988-02-29/ business/8804030539_1_working-class-women-skilled-men-and-women.

Kwon, Y. H. (1994). Feeling toward one's clothing and self-perception of emotion, sociability, and work competency. Journal of Social Behavior \& Personality, 9(1), 129-139.

Levy, S. J. (1959). Symbols for sale. Harvard Business Review, 37(4), 117-124. Retrieved 25 Aug 2015. http://www.uibk.ac.at/ smt/marketing/brandresearchlab2/files/symbolsforsale_levy.pdf.

Lynch, K. D. (2007). Modeling role enactment: linking role theory and social cognition. Journal for the Theory of Social Behaviour, 37(4), 379-399. doi:10.1111/j.1468-5914.2007.00349.

MacLean, N. (2006). Freedom is not enough: the opening of the American workplace. Cambridge: Harvard University Press.

Mansfield, P. K., Koch, P. B., Henderson, J., Vicary, J. R., Cohn, M., \& Young, E. W. (1991). The job climate for women in traditionally male blue-collar occupations. Sex Roles, 25(1-2), 63-79. doi:10.1007/BF00289317.

McCall, G. J., \& Simmons, J. L. (1978). Identities and interactions: an examination of human associations in everyday life. New York: Free Press.

Miller-Spillman, K. A., Reilly, A., \& Hunt-Hurst, P. (2012). The meanings of dress. New York: Fairchild.

National Association of Women in Construction (2013). Statistics of women in construction. National Association of Women in Construction. Retrieved 25 Aug 2015. http://www.nawic.org/nawic/Future_Projections1.asp.

Paap, K. (2006). Working construction: why white working-class men put themselves — and the labor movement-in harm's way. Ithaca: Cornell University Press.

Pettinger, L. (2005). Gendered work meets gendered goods: selling and service in clothing retail. Gender, Work \& Organization, 12(5), 460-478. doi:10.1111/j.1468-0432.2005.00284.

Postlethwaite, D. (2014, June). Dispelling automation myths. Welding Journal. Retrieved 25 Aug 2015. https://app.aws.org/ wj/2014/WJ_2014_06/index.html\#/1/.

Statistica (2014). US apparel and accessories retail e-commerce revenue from 2012 to 2018 (in billion US dollars). Statistica. Retrieved 25 Aug 2015. http://www.statista.com/statistics/278890/ us-apparel-and-accessories-retail-e-commerce-revenue. 
Stryker, S. (2001). Traditional symbolic interactionism, role theory, and structural symbolic interactionism: the road to identity theory. In J. H. Turner (Ed.), Handbook of sociological theory (pp. 211-231). New York: Kluwer Academic/Plenum Publishers.

Tork, N. (2008). The effects of gendered stressors on female construction workers' occupational health and safety: a re-analysis of qualitative data. Unpublished doctoral dissertation, University of Cincinnati, Ohio.

United States Department of Labor (2012). Latest annual data: Women's bureau. United States Department of Labor. Retrieved 25 Aug 2015. http://www.dol.gov/wb/stats/recentfacts.htm\#rates.

Van Leeuwen, T., \& Jewitt, C. (Eds.). (2001). The handbook of visual analysis. Thousand Oaks: Sage.

Wagner, H., Kim, A. J., \& Gordon, L. (2013). Relationship between personal protective equipment (PPE), self-efficacy, and job satisfaction of women in the building trades. Journal of Construction Engineering and Management,. doi:10.1061/ (ASCE)CO.1943-7862.0000739

Walshok, M. J. (1981). Blue-collar women: pioneers in the male frontier. Garden City: Anchor/Doubleday.

\section{Submit your manuscript to a SpringerOpen ${ }^{\circ}$} journal and benefit from:

- Convenient online submission

- Rigorous peer review

- Immediate publication on acceptance

- Open access: articles freely available online

- High visibility within the field

- Retaining the copyright to your article 